\title{
KARAKTERISTIK MUTU DAN PEMASARAN IKAN PINDANG TONGKOL DI KOTA BOGOR
}

\author{
Oleh : \\ Sobariah, Hendria Suhrawardan, Alvi Nur Yudisttira \\ Dosen Jurusan Penyuluhan Perikanan Sekolah Tinggi Perikanan
}

\begin{abstract}
ABSTRAK
Pemikiran dasar yang digunakan dalam kajian ini adalah apakah ikan pindang yang selama ini dikonsumsi di wilayah Bogor, masih tergolong ikan pindang yang memiliki mutu baik sesuai karakteristik mutu ikan pindang dan sejauhmana tingkat pemasaran untuk ikan pindang yang ada di dua pasar, yaitu pasar Anyar dan pasar Bogor.ini dapat tergolong ikan pindang yang di pasarkan secara dominan. Pengujian mutu ikan pindang dilakukan dengan uji organoleptik, uji kadar air, uji kadar lemak serta identifikasi pemasaran ikan pindang pada pemasok ikan pindang di wilayah Bogor.

Dari hasil penelitian yang dilakukan pada uji mutu ikan pindang ( uji organoleptik dan uji kadar air) dengan parameter : penampakan diperoleh nilai rata-rata nlai $6,4 \%$ fostur tubuh ikan, utuh, besih agak kurang rapih dan agak menarik. Parameter aroma memperoleh nilai rata-rata 7.5\% harum, hampir netral, Rasa sangat enak dan gurih dengan rata-rata nilai $7.6 \%$, Konsistensi dengan nilai $7.8 \%$ untuk daging ikan diperoleh, padat, kompak, lentur, agak lembab. Untuk lendir yang dikeluarkan tubuh ikan agak tipis, tidak jelas, dan tidak berbau dengan nilai $8.3 \%$ sedangkan kapang diperoleh nilai rata-rata 9.0\% untuk ikan pindang yang diuji ternyata kapang tidak ada. Dari hasil identifikasi pemasaran ternyata dipasar Anyar dan Pasar Bogor jumlah ikan pindang tongkol yang diserap konsumen sebanyak $5000 \mathrm{~kg}$ (5 ton) perhari dengan jumlah penjual sebanyak 14 orang. Jadi dilihat dari hasil pemasaran ikan pindang tongkol pada pasar yang ada diwilayah Bogor dan sekitar, ikan pindang tongkol sangat dominan atau menduduki pasaran tertinggi dibandingkan ikan pindang lain.
\end{abstract}

Kata Kunci : kualitas, pasar, sebaran

\section{PENDAHULUAN}

\section{Latar Belakang}

Ikan pindang merupakan hasil olah yang cukup popular di Indonesia. Olahan tradisional ini menempati urutan kedua setelah ikan asin. Ikan pindang diminati oleh masyarakat dikarenakan harga jual yang cukup murah dibandingkan dengan olahan lain yang memiliki harga yang lebih mahal. Proses pengolagan ikan pindang yang ada di masyarakat sangat beragam. Pada umumnya ikan yang merupakan bahan baku utama dalam proses pemindangan merupakan ikan laut. Pada proses pemindangan, ikan direbus atau dikukus dengan tambahan garam. Penambahan gara, di maksud untuk memperpanjang umur simpan dan meningkatkan cita rasa ikan pindang yang di olah.

Ikan pindang dengan bahan baku ikan tongkol merupakan salah satu jenis olahan 
ikan pindang yang banyak ditemukan di pasar tradisional yang ada di Kota Bogor, sehingga perlu dilakukan kajian untuk mengetahui karakteristik mutu dan tingkat pemasaran ikan pindang tongkol yang di jual di Pasar Anyar dan Pasar Bogor, Kota Bogor. Dipilihnya dua lokasi pasar tersebut dikarenakan dua pasar tersebut merupakan pasar tradisional yang letaknya berada di tengah kota Bogor.

\section{Tujuan}

Tujuan dari penelitian ini adalah :

1. Mengetahui karakteristik mutu ikan pindang tongkol yang dijual di dua lokasi pasar, yaitu Pasar Anyar dan Pasar Bogor, Kota Bogor.

2. Mengetahui tingkat pemasaran ikan pindang tongkol yang dijual di Pasar Anyar dan Pasar Bogor, Kota Bogor.

\section{METODE PENELITIAN}

\section{Waktu dan Tempat Penelitian}

Penelitian dilaksanakan mulai tanggal 6 Agustus 2008 sampai dengan 30 November 2008. Penelitian dilakukan di Pasar Anyar dan Pasar Bogor, Kota Bogor. Penguji mutu ikan pindang tongkol dilakukan di Laboratorium Lingkungan, Sekolah Tinggi Perikanan, Jurusan Penyuluhan Perikanan Bogor.

\section{Jenis dan Sumber Data Penelitian}

Jenis data penelitian dibagi menjadi dua, yaitu data tentang karakteristik mutu dan data tentang system pemasaran. Data tentang system pemasaran merupakan data yang akan memperlihatkan system pemasaran ikan pindang yang ada di Pasar Anyar dan Pasar Bogor.

\section{Sumber Data Penelitian}

Data yang dipergunakan dalam penelitian ini adalah data primer dan data sekunder. Data primer diperoleh dari hasil penguji laboratorium dan hasil wawancara dengan para pedagang yang ada di pasar serta petugas dari Pemerintah Kota Bogor yang mengelola Pasar Bogor dan Pasar Anyar. Data sekunder diperoleh dari Dinas Perindustrian dan Perdagangan Kota Bogor.

\section{Alat dan Bahan}

Alat dan bahan yang diperlakukan dalam penelitian ini terbagi menjadi dua. Alat dan bahan yang dipergunakan dibagi berdasarkan jenis data yang diambil.

\section{Alat dan bahan untuk data karakteristik mutu ikan pindang tongkol}

Alat dan bahan yang diperlukan dalam pengambilan data karakteristik mutu ikan pindang tongkol meliputi peralatan dan bahan yang diperlukan dalam pengujian laboratorium. Alat-alat yang diperlukan untuk menguji mutu antara lain : pembakaran spiritus, oven, desikator, mortar, timbangan analitik, hot plate,dan alat-alat gelas. Sedangkan bahan yang diperlukan dalam pengujian mutu ikan pindang antara lain : ikan pindang tongkol, Nutrien Agar (TSA), $\mathrm{NaCl}$, $\mathrm{H}_{2} \mathrm{SO}_{4}, \mathrm{NaOH}, \mathrm{H}_{3} \mathrm{BO}_{3}, \mathrm{HCl}$, Hexana, kertas saring, kapas, dan TCA.

\footnotetext{
Alat dan bahan untuk pengambilan data sistem pemasaran ikan pindang tongkol

Alat dan bahan yang diperlukan dalam pengambilan data pemasaran ikan pindang tongkol meliputi alat tulis kantor dan recorder untuk merekam selama proses wawancara. Dalam pengolahan data diperlukan alat bantu
} 
berupa komputer yang dilengkapi bengan perangkat lunak untuk mengolah data.

\section{Metode Pengambilan Data}

Karakteristik mutu ikan pindang diperoleh dengan melakukan penguji di laboratorium pada beberapa prameter meliputi : penguji secara organoleptik, dan penguji kadar air. Ikan pindang tongkol yang diuji merupakan ikan pindang tongkol yang dibeli secara acak dari beberapa pedagang yang ada di Pasar Anyar dan Pasar Bogor.

\section{Pengujian Organoleptik}

Pengujian organoleptik dilakukan dengan melakukan pengujian pada parameter penampakan, aroma, rasa, konsistensi daging, lendir, dan kapang. Panelis yang akan memberikan penilaian terhadap seluruh parameter yang diujikan. Pada dasarnya pamindangan ikan merupakan pengawetan sekaligus pengolahan ikan dengan menggunakan teknik penggaraman dan pemanasan. Garam yang digunakan berperan sebagai pengawet sekaligus memperbaiki cita rasa ikan dan menyebabkan tekstur ikan berubah menjadi lebih kompak, sedangkan pemanasan mematikan sebagian besar bakteri pada ikan, terutama bakteri pembusuk dan patogen (Wibowo 1995).

Cara pengukuran mutu pangan dapat dibedakan menjadi dua, yaitu pengukuran secara objektif dan pengukuran secara subjektif. Pengukuran secara objektif dilakukan dengan menggunakan alat dan secara subjektif dengan menggunakan indera yang meliputi rupa, bau, tekstur, dan rasa (Soekarno 1985). Penurunan mutu organoleptik pada pindang ikan ditandai dengan timbulnya bau busuk dan tengik, timbulnya lendir dan kapang pada kulit ikan, serta tekstur ikan yang lembek dan tidak kompak. Penilaian mutu organoleptik pindang ikan didasarkan pada score sheet organoleptik pindang ikan (SNI 1991).

\section{Pengujian kadar air (AOAC, 1984)}

Pengukuran kadar air dilakukan dengan menggunakan oven pada suhu $102^{\circ} \mathrm{C}$ selama satu jam dan didinginkan dalam desikator lalu di timbang. Contoh yang akan ditentukan kadar airnya ditimbang kurang lebih 2 g pada cawan yang telah diketahui beratnya tersebut dan kemudian dikeringkan dalam oven suhu $102^{\circ} \mathrm{C}$ selama 8 jam. Kemudian cawan dimasukan ke dalam desikator selama 30 menit, lalu timbang. Setelah ditimbang dipanaskan kembali ke dalam desikator selama 30 menit dan timbang kembali. Pengukuran berat cawan dilakukan sampai dicapai berat konstan.

Kadar air dihitung sebagai pengurangan berat contoh selama dalam oven dan dihitung sebagai pengurangan berat contoh selama dalam oven dan dihitung dengan rumus sebagai berikut :

$$
\text { Kadar air }(\% \mathrm{bb})=\frac{(\mathrm{A}-\mathrm{B})}{\mathrm{C}} \times 100 \%
$$

Keterangan :

$\mathrm{A}=$ Berat wadah dan contoh mulamula $(\mathrm{g})$

$\mathrm{B}=$ Berat wadah dan contoh setelah dikeringkan $(\mathrm{g})$

$$
\mathrm{C}=\text { Berat contoh mula-mula }(\mathrm{g})
$$

\section{Penguji Kadar Lemak (AOAC, 1984)}

Labu lemak yang ukurannya sesuia dengan alat ektraksi soxhlet dikeringkan dalam oven. Kemudian didinginkan dalam 
desikator dan ditimbang hingga bobot tetap. Sebanyak $5 \mathrm{~g}$ sampel dibungkus dengan kertas saring, kemudian ditutup dengan kapas wool yang bebas lemak. Kertas saring yang berisi sampel tersebut dimasukan dalam alat ektraksi soxhlet, kemudian dipasang alat kondensor ditasnya dan labu lemak di bawahnya.

Pelarut dituangkan ke dalam labu lemak secukupnya sesuai dengan ukuran yang digunakan. Selanjutnya dilakukan refluks minimum 5 jam sampai pelarut yang turun kembali ke labu lemak berwarna jernih. Pelarut yang ada di dalam labu lemak didestilasi dan ditampung. Kemudian labu lemak yang berisi hasil ekstraksi dipanaskan dalam oven pada suhu $105^{\circ} \mathrm{C}$. Selanjutnya didinginkan dalam desikator dan dilakukan penimbangan hingga diperoleh bobot tetap.

Berat Lemak (gr)

Kadar Lemak $(\%)=\longrightarrow 100 \%$

Berat Sampel (gr)

Metode pengambilan data pemasaran ikan pindang

Metode yang digunakan dalam pengambilan data adalah dengan melakukan observasi langsung dengan memberikan quesioner kepada penjual, pembeli dan Dinas Pasar Kota Bogor. quesioner berisikan pertanyaan tentang jumlah ikan yang dijual dalam satu hari, asal ikan yang di jual beserta frekuensi penyediaan ikan pindang tongkol. Kuesioner yang diberikan kepada pembeli berisi pertanyaan tentang jumlah ikan yang dibeli, beserta frekuensi pembelian. Kuesioner yang diisi oleh petugas dari Dinas Pasar berisi data tentang jumlah pemasok ikan pindang, asal pemasok, jumlah penjual, dan omzet penjualan ikan pindang. Selain itu juga diambil data berdasarkan observasi langsung meliputi jumlah penjual, jumlah pembeli. Selain ke Dinas Pasar di kota Bogor juga ke pemasok yang ada di Bogor

\section{Metode Pengolahan Data}

Data yang diperoleh dan ditampilkan langsung dalam bentuk tabulasi disajikan secara deskriptif.

\section{HASIL DAN PEMBAHASAN}

\section{Karakteristik Mutu Organoleptik}

Pengujian organoleptik ikan pindang tongkol bertujuan untuk mengetahui karakteristik mutu organoleptik ikan pindang tongkol. Karakteristik mutu irganoleptik yang dinilai adalah penampakan, rasa, aroma, konsistensi, lendir, dan kapang. Panelis yang dipergunakan dalam pengujian ini adalah panelis semi terlatih. Panelis merupakan taruna Sekolah Tinggi Perikanan Jurusan Penyuluhan Perikanan semester 6. Panelis yang dipergunakan telah sering melakukan pengujian organoleptik pada praktikum yang dilaksanakan di lingkungan kampus.

Berdasarkan penilaian organoleptik yang dilakukan oleh panelis terhadap 6 parameter organoleptik ikan tongkol diperoleh data yang tersaji pada Tabel 3 . 
Tabel 3. Nilai Hasil Uji Organoleptik Ikan Pindang Tongkol

\begin{tabular}{|l|l|l|l|}
\hline No & Parameter & $\begin{array}{l}\text { Nilai Rata- } \\
\text { Rata }\end{array}$ & Deskripsi \\
\hline 1 & Penampakan & 6.4 & Utuh, bersih, kurang rapi, agak menarik \\
2 & Aroma & 7.5 & Harum segar, hampir netral \\
3 & Rasa & 7.6 & Sangat enak, gurih \\
4 & Konsistensi & 7.8 & Padat, kompak, lentur, agak lembab \\
5 & Lendir & 8.3 & Lendir tipis, tidak jelas, tidak berbau \\
6 & Kapang & 9.0 & Tidak ada \\
\hline
\end{tabular}

Sumber: Data hasil diolah th 2009

Berdasarkan tabel 3 tersebut maka dapat diketahui sejauhmana unsur-unsur yang diujikan dalam karakteristik Ikan Pindang Tongkol yang ada di Bogor antara lain :

\section{Parameter Penampakan}

Penampakan merupakan parameter pertama yang berkesan pada pikiran panelis yang akan memberilan penilaian. Pada hasil uji orgsnoleptik yang dilakukan, penampakan ikan pindang tongkol memperoleh nilai 6.4. Deskripsi dari nilai tersebut adalah utuh, bersih, kurang rapi, agak menarik. Ikan pindang tongkol yang dijual di Kota Bogor secara umum memiliki kondisi yang masih utuh dan bersih. Namun demikian penampakan ikan pindang tersebut kurang rapi dikarenakan ikan bersinggungan antara satu dengan yang lain, sehingga bentuk dan warna permukaan menjadi tidak rata.

Kondisi ini dapat memppengaruhi konsumen dalam memilih ikan pindang yang akan dibeli. Meski nilai yang diperoleh dari pengujian organoleptik telah memenuhi Standar Nasional Indonesia, namun perlu dilakukan perbaikan penampilan pada ikan pindang agar mampu meningkatkan daya tarik terhadap konsumen.

Parameter Aroma
Aroma ikan pindang tongkol mendapatkan nilai rata-rata 7.5 dari panelis. Panelis memiliki perpepsi bahwa ikan pindang tersebut harum, segar, namun hampir netral. Ikan laut secara umum memang memiliki aroma yang lebih kuat dari ikan yang ada di perairan tawar. Proses pengolahan yang terlalu panjang dan lama dapat mengurangi bahan volatil yang memberikan aroma pada ikan tesebut. Pindang ikan tongkol yang dijual di Kota Bogor masih memiliki aroma harum dan segar khas ikan pindang yang sudah mulai berkurang. Hal ini dapat dimungkinkan oleh hilangnya zat volatil yang ada di dalam daging ikan selama pengangkutan hingga di jual di pasar kepada konsumen.

\section{Parameter Rasa}

Pada penilaian organoleptik ikan pindang tongkol pada parameter rasa, nilai rata-rata yang diberikan oleh panelis adalah 7.6. Nilai ini tidak jauh berbeda dengan nilai pada parameter aroma. Parameter rasa dalam perpesi merupakan parameter yang sangat dipengaruhi oleh aroma.

Menurut panelis yang memberikan penilaian, ras aikan pindang tongkolmasih sangat enak dan gurih. Aroma yang harum dan segar membuat panelis yakin bahwa ikan 
pindang memang masih memiliki rasa yang sangat enak dan gurih. Ikan pindang tongkol merupakan produk olahan yang hanya menggunakan garam sebgai bahan tambahan dlam proses perebusannya. Rasa ikan pindang tongkol yang dihasilkan merupakan proses perpaduan antara rasaikan tongkol sendiri dengan garam sebagai penguat rasa.

\section{Parameter Konsistensi}

Konsistensi ikan pindang tongkol masih dalam kondisi yang sangat baik. Ratarata nilai yang diberikan oleh panelis adalah 7.8 dengan deskripsi padat, kompak, lentur, agak lembab,. Konsistensi daging belum mengalami kerusakan. Kondisi ini juga telah tergambar pada parameter penampakan. Penampakan ikan pindang tongkol yang masih uth menunjukan bahwa daging ikan masih dalam kondisi baik secara fisik.

Daging ikan pindang tongkol yang telah dimasaak mengalami penurunan kadar air. Namun berbeda dengan ikan asin yang mengalami dihidrasi karena pemanasan, ikan pindang tongkol yang telah dimasak akan menjadi padat dan kompak namun lltetap lembab.

\section{Parameter Lendir}

Lendir dapat dijadikan sebagai indikator jumlah bakteri pembusuk yang ada di dalam ikan pindang tongkol. Bakteri
Micrococcus merupakan bakteri utama penghasil lendir dalam ikan pindang ikan tongkol. (Heruwati 1980).

Penilaian organoleptik terhadap ikan pindang tongkol menunjukan bahwa lendir masih tipis, samar-samar, serta tidak bau. Kondisi ini menunjukan bahwa ikan pindang tongkol masih dalam kondisi segar. Produksi bakteri pembusuk masi sangat rendah.

\section{Parameter Kapang}

Proses kemunduran mutu ikan pindang ditandai dengan timbulnya lendir dan kapang. Berdasarkan penilaian yang dilakukan oleh panelis, belum nampak kapang pada ikan pindang tongkol yang dinilai. Hal ini menunjukan bahwa ikan pindang tongkol tersebut memang dalam keadaan yang masih baru.

Penilaian di atas sesuai dengan persyaratan mutu Standar Internasional Indonesia. Dalam SNI dipersyaratkan bahwa ikan pindang tongkol yang baik tidak memperoleh nilai negatif dalam pengujian terhadap kapang secara organeleptik.

\section{Karakteristik Mutu Kimiawi}

Pengujian kadar air yang dilakukan terhadap ikan pindang tongkol dengan menggunkan metode gravimetri (AOAC, 1984) memperoleh hasil yang tersaji pada tabel di bawah.

Tabel 4. Nilai Hasil Uji Kadar Ikan Pindang Tongkol

\begin{tabular}{|lcc|}
\hline No & Ulangan Pengujian & Kadar Air (\%) \\
\hline 1 & Simplo & $\mathbf{4 6 , 1 8}$ \\
2 & Duplo & 45,77 \\
3 & Triplo & 44,87 \\
\hline & Rata-Rata & $\mathbf{4 5 , 6 1}$ \\
\hline
\end{tabular}

\section{Sumber : data diolah}


Berdasarkan tabel 4 diatas hasil pengujian tersebut telah memenuhi persyaratan Standar Nasional Indonesia. Nilai rata kadar air ikan pindang togkol adalah $45,61 \%$. Nilai ini jauh lebih rendah dari kadar air maksimal yang dipersyaratkan dalam SNI yakni sebesar $70 \%$.

Kadar air dalam dagig ikan yang rendah akan menghambat proses kemunduran mutu akibat aktivitas mikroorganisme. Pindang dengan kadar garam rendah dan kadar air tinggi segera akan mengalami pelendiran disamping timbulnya kapang (Hanafiah dan llyas, 1978). Kondisi ini tergambar dari hasil pengjian organoleptik pada parameter lendir kapang. Pada hasil pengujian pada dua patrameter tersebut menunjukan hasil yang mendukung hasil pengujian kadar air.

\section{Pemasaran Ikan Pindang Tongkol}

Konsep-konsep inti pemasaran meliputi : kebutuhan, keinginan, permintaan, produksi, utilitas, nilai dan kepuasan; pertukaran, transaksi, dan hubungan pasar, pemasaran dan pasar. Kita dapat membedakan antara kebutuhan, keinginan, dan permintaan. Kebutuhan adalah suatu keadaan dirasakannya ketidak puasan dasar tertentu. Keinginan adalah kehendak yang kuat akan pemuas yang spesifik terhadap kebutuhan-kebutuhan yang lebih mendalam. Sedangkan permintaan adalah keinginan akan produksi yang spesifik yang didukung dengan kemampuan dan kesediaan untuk membelinya.
Dalam Kamus Besar Bahasa Indonesia, "pasar" diartikan sebagai suatu tempat jual beli.Dalam pustaka lain, pasar diartikan sebagai semua kegiatan yang bertujuan untuk melancarkan arus barang / jasa dari produsen ke konsumen secara paling efisien dengan maksud untuk menciptakan pemintaan yang efisien (Wiratmo 1999).

Pemasaran adalah suatu proses sosial dan manajerial yang di dalamnya individu dan atau kelompok mendapatkan apa yang mereka butuhkan dan mereka inginkan dengan menciptakan produk yang bernilai dengan pihak lain (Kotler 1998).

Bauran Pemasaran merupakan interaksi 4 variabel utama sistem pemasaran yaitu : produksi / jasa, penentuan harga, distribusi, promosi produk atau jasa, dengan mempertimbangkan variabel-variabel lain : kemasan, cap, disain (bentuk \& warna), pengembangan produk baru.

Pemasaran ikan pindang di Bogor sangat dominan hal ini dapat dilihat dari hasil penjualan ikan pindang tiap hari di Pasar Bogor yang berasal dari pengolah ikan pindang di wilayah Bogor itu sendiri dan merupakan pemasok terbesar diseluruh wilayah Bogor yaitu dari pengolah Bapak Nur, dengan hasil penjualan ikan pindang setiap hari di kedua pasar untuk jenis ikan pindang tongkol seperti terlihat dari hasil identifikasi tersaji pada table 5 . 
Tabel 5 : DATA PENJUALDAN JENIS IKAN PINDANG DI PASAR KOTA /KABUPATEN BOGOR

\begin{tabular}{|c|c|c|c|c|c|c|c|c|c|c|c|c|c|c|c|c|c|c|c|c|c|c|c|c|}
\hline \multirow[t]{2}{*}{ NO } & \multirow[t]{2}{*}{ LOKASI } & \multicolumn{2}{|c|}{$\begin{array}{c}\text { NAMA } \\
\text { PENJUAL } \\
\end{array}$} & \multicolumn{18}{|c|}{ JENIS IKAN } & \multirow[b]{2}{*}{ TOTAL } & \multirow[b]{2}{*}{ KG } & \multirow[b]{2}{*}{ KET } \\
\hline & & & & NAMA & \multicolumn{2}{|c|}{ JUMLAH } & NAMA & \multicolumn{2}{|c|}{ JUMLAH } & NAMA & \multicolumn{2}{|c|}{ JUMLAH } & NAMA & \multicolumn{2}{|c|}{ JUMLAH } & NAMA & \multicolumn{2}{|c|}{ JUMLAH } & NAMA & \multicolumn{2}{|c|}{ JUMLAH } & & & \\
\hline 1 & $\begin{array}{l}\text { PASAR } \\
\text { ANYAR }\end{array}$ & 1 & AMAN & Tongkol/Cakalang & 150.0 & $\mathrm{~kg}$ & layang & & & Bandeng & & & Etem & & & Bentong & & & Kembung & & & & & $\begin{array}{l}\text { Pindang } \\
\text { dari }\end{array}$ \\
\hline & & 2 & USMAN & Tongkol/Cakalang & 300.0 & $\mathrm{~kg}$ & layang & & & Bandeng & & & Etem & & & Bentong & & & Kembung & & & & & $\begin{array}{l}\text { Pengolah } \\
\text { ikan }\end{array}$ \\
\hline & & 3 & BUNBUN & Tongkol/Cakalang & 250.0 & $\mathrm{~kg}$ & layang & & & Bandeng & & & Etem & & & Bentong & & & Kembung & & & & & (bp. Nur \\
\hline & & 4 & OJOS & & & & layang & 50 & $\mathrm{~kg}$ & Bandeng & 25 & $\mathrm{~kg}$ & Etem & 50 & $\mathrm{~kg}$ & Bentong & 20 & $\mathrm{~kg}$ & Kembung & 55 & $\mathrm{~kg}$ & 200 & $\mathrm{~kg}$ & \\
\hline & & JUI & $\mathrm{LAH}$ & & 700.0 & & & & & & & & & & & & & & & & & & & \\
\hline 2 & $\begin{array}{l}\text { PASAR } \\
\text { BOGOR } \\
\end{array}$ & 1 & PUDIN & Tongkol/Cakalang & 2 & $\mathrm{~kg}$ & & & & & & & & & & & & & & & & 2 & $\mathrm{~kg}$ & \\
\hline & & 2 & ENDA & Tongkol/Cakalang & 100 & $\mathrm{~kg}$ & & & & & & & & & & & & & & & & 100 & & \\
\hline & & 3 & EMUH & Tongkol/Cakalang & 300 & $\mathrm{~kg}$ & & & & & & & & & & & & & & & & 300 & & \\
\hline & & 4 & DADE & Tongkol/Cakalang & 600 & $\mathrm{~kg}$ & & & & & & & & & & & & & & & & 600 & & \\
\hline & & 5 & RAHMAT & Tongkol/Cakalang & 300 & $\mathrm{~kg}$ & & & & & & & & & & & & & & & & 300 & & \\
\hline & & 6 & AGUS & Tongkol/Cakalang & 200 & $\mathrm{~kg}$ & & & & & & & & & & & & & & & & 200 & & \\
\hline & & 7 & AAN & Tongkol/Cakalang & 200 & $\mathrm{~kg}$ & & & & & & & & & & & & & & & & 200 & & \\
\hline & & 8 & ANAY & Tongkol/Cakalang & 300 & $\mathrm{~kg}$ & & & & & & & & & & & & & & & & 300 & & \\
\hline & & 9 & $\begin{array}{l}\text { UJANG } \\
\text { AYI }\end{array}$ & Tongkol/Cakalang & 200 & $\mathrm{~kg}$ & & & & & & & & & & & & & & & & 200 & & \\
\hline & & 10 & DADANG & Tongkol/Cakalang & 100 & $\mathrm{~kg}$ & & & & & & & & & & & & & & & & 100 & & \\
\hline & & & rang & & 5.000 & $\mathrm{~kg}$ & & & & & & & & & & & & & & & & 5000 & $\mathrm{Kg}$ & \\
\hline
\end{tabular}




\begin{tabular}{|c|c|c|c|c|c|c|c|c|c|c|c|c|c|c|c|c|c|c|c|c|c|c|c|c|}
\hline 3 & $\begin{array}{l}\text { PASAR } \\
\text { CISARUA }\end{array}$ & 1 & EEN & Tongkol/Cakalang & 1000 & $\mathrm{~kg}$ & layang & 150 & $\mathrm{~kg}$ & Bandeng & 100 & $\mathrm{~kg}$ & Etem & 50 & $\mathrm{~kg}$ & Bentong & 100 & $\mathrm{~kg}$ & Kembung & 100 & $\mathrm{~kg}$ & 1500 & $\mathrm{Kg}$ & Mengolah \\
\hline & & 2 & CuWO & Tongkol/Cakalang & 400 & $\mathrm{~kg}$ & layang & & & Bandeng & & & Etem & & & Bentong & & & Kembung & & & 400 & & Sendiri \\
\hline & & & & & & & & & & & & & & & & & & & & & & 0 & & $\begin{array}{l}\text { lkannya } \\
\text { dr }\end{array}$ \\
\hline \multirow[t]{3}{*}{4} & $\begin{array}{l}\text { PASAR } \\
\text { CIAMPEA }\end{array}$ & 1 & MAMAN & Tongkol/Cakalang & 200 & $\mathrm{~kg}$ & layang & 100 & $\mathrm{~kg}$ & Bandeng & 100 & $\mathrm{~kg}$ & Etem & 100 & $\mathrm{~kg}$ & Bentong & 100 & $\mathrm{~kg}$ & Kembung & 100 & $\mathrm{~kg}$ & 700 & $\mathrm{Kg}$ & Bp.Nur di \\
\hline & & 2 & DIDIN & Tongkol/Cakalang & 300 & $\mathrm{Kg}$ & layang & 50 & $\mathrm{~kg}$ & Bandeng & 50 & $\mathrm{~kg}$ & Etem & 20 & $\mathrm{~kg}$ & Bentong & 30 & $\mathrm{~kg}$ & Kembung & 50 & $\mathrm{~kg}$ & 500 & $\mathrm{Kg}$ & Yasmin \\
\hline & & & & & & & & & & & & & & & & & & & & & & 0 & & \\
\hline \multirow[t]{2}{*}{5} & $\begin{array}{l}\text { PASAR } \\
\text { LEUWILIANG }\end{array}$ & 1 & OBON & Tongkol/Cakalang & 200 & $\mathrm{Kg}$ & layang & 100 & $\mathrm{~kg}$ & Bandeng & 50 & $\mathrm{~kg}$ & Etem & 20 & $\mathrm{~kg}$ & Bentong & 30 & $\mathrm{~kg}$ & Kembung & 50 & $\mathrm{~kg}$ & 450 & $\mathrm{Kg}$ & \\
\hline & & & & & & & & & & & & & & & & & & & & & & 0 & & \\
\hline \multirow[t]{3}{*}{6} & $\begin{array}{l}\text { PASAR } \\
\text { JASINGA }\end{array}$ & 1 & NANA & Tongkol/Cakalang & 400 & $\mathrm{Kg}$ & layang & 50 & $\mathrm{~kg}$ & Bandeng & 10 & $\mathrm{~kg}$ & Etem & 20 & $\mathrm{~kg}$ & Bentong & 10 & $\mathrm{~kg}$ & Kembung & 10 & $\mathrm{~kg}$ & 500 & $\mathrm{~kg}$ & \\
\hline & & 2 & DEDI & & & & layang & 50 & $\mathrm{~kg}$ & Bandeng & 50 & $\mathrm{~kg}$ & Etem & 20 & $\mathrm{~kg}$ & Bentong & 30 & $\mathrm{~kg}$ & Kembung & 50 & $\mathrm{~kg}$ & 200 & $\mathrm{~kg}$ & \\
\hline & & & & & & & & & & & & & & & & & & & & & & 0 & & \\
\hline \multirow[t]{3}{*}{7} & $\begin{array}{l}\text { PASAR } \\
\text { CIGUDEG }\end{array}$ & 1 & MAMAN & Tongkol/Cakalang & & & layang & 50 & $\mathrm{~kg}$ & Bandeng & 50 & $\mathrm{~kg}$ & Etem & 20 & $\mathrm{~kg}$ & Bentong & 30 & $\mathrm{~kg}$ & Kembung & 50 & $\mathrm{~kg}$ & 200 & $\mathrm{~kg}$ & \\
\hline & & 2 & AWANG & Tongkol/Cakalang & & & layang & 100 & $\mathrm{~kg}$ & Bandeng & 50 & $\mathrm{~kg}$ & Etem & 20 & $\mathrm{~kg}$ & Bentong & 30 & $\mathrm{~kg}$ & Kembung & 50 & $\mathrm{~kg}$ & 250 & $\mathrm{~kg}$ & \\
\hline & & & JUMLAH & & 2500 & & & 650 & & & 485 & & & 320 & $\mathrm{~kg}$ & & 380 & & & 515 & & 4850 & & \\
\hline
\end{tabular}

Sumber : Pengolah ikan pindang di Yasmin Bogor 
Berdasarkan tabel diatas, bahawa penjual ikan di dua Pasar yaitu pasar Bogor dan Pasar Anyar sebanyak 14 orang dengan hasil penjualan ikan pindang tongkol/cakalang sebanyak $5000 \mathrm{~kg}$ (5 ton) perhari jika dibandingkan dengan pasar-pasar lain yang ada di wilayah Bogor,seperti pasar Cisarua, psr.Cibungbulang, Psr. Parung, Psr.Ciampea, Jasinga, Psr, Leuwiliang, Psr. Nanggung, Psr. Cigudeg, Psr. Babakan Madang, ternyata memang dominan ikan pindang dengan jumlah $2500 \mathrm{~kg}$, sedangkan jenis ikan pindang lain sebanyak $2850 \mathrm{~kg}$, jadi dengan melihat data yang ada ternyata ikan pindang tongkol memang lebih di sukai konsumen pennduduk Kota Bogor dan sekitarnya, didukung dengan hasil pengujian sebelumnya yang dapat dilihat dari data laboratorium menyatakan bahwa karakteristik ikan pindang lebih enak, harum segar dan masih segar. Di lihat dari faktorfaktor penentu pasar, maka faktor-faktor yang perlu diperhatikan dalam penentuan harga adalah biaya, diskon, laba dan pengangkutan yang realistik. Secara nyata hasil penjualan menunjukan tingkat pemasaran yang dominan hal ini dapat diketahui dengan harga yang berlaku saat itu.

\section{KESIMPULAN DAN SARAN}

\section{Kesimpulan}

Ikan pindang yang dipasarkan di Kota Bogor masih dalam keadaan utuh, bersih. Namun kurang rapi. Ikan pindang tersebut masih memiliki rasa yang sangat enak dan gurih dengan aroma yang harum dan segar meski agak netral. Kondisi daging ikan juga masih padat, kompak, dan agak lembab.
Permukaan kulit dilapisi lendir tipis yang tidak berbau serta belum ditumbuhi oleh kapang.

Kadar air dalam daging ikan pindang tongkol sebesar 45,61\%, jauh lebih rendah dari kadar air maksimal yang dipersayaratkan oleh SIN. Kondisi ini señalan dengan hasil uji organoleptik pada parameter lendir dari kapang. Karakteristik ikan pindang tongkol yang di pasarkan di Kota Bogor telah memenuhi beberapa kondisi yang dipersyaratkan oleh SNI. Parameter dipenuhi antara lain parameter organoleptik dan parameter kimia.

Dari hasil identifikasi pasar ternyata ikan pindang tongkol lebih menguasai pasar, terutama pada kedua pasar yaitu pasar Anyar dan Pasar Bogor dengan hasil penjualan perhari sebanyak $5000 \mathrm{~kg}$ (5 ton) dengan jumlah penjual sebanyak 14 orang.

\section{Saran}

Perlu dilakukan penelitian lanjutan tentang kemungkinan adanya kandungan logam berat dalam daging ikan. Hal ini dikarenakan proses pengolahan yang tidak memperhatikan aspek keamanan pangan. Untuk pemasaran dapat diteliti lebih lanjut sejauhmana ikan pindang tongkol dapat tersalur keluar Kota Bogor.

\section{DAFTAR PUSTAKA}

Afrianto E, Liviawaty E. 1989. Pengawetan dan pengolahan Ikan. Jakarta: Kanisus. 
Hanifah TAR. Llyas S. 1980. Mengamati berbagai aspek selama proses pemindangan garam. Dalam Teknologi Pengolahan Pindang. Prosiding Seminar; Jakarta, 1-2 Des 1980. Jakarta : Lembaga Penelitian dan Teknoogi Perikanan. Balai Penelitian dan Pengembangan Pertanian. Departemen Pertanian.

Kotler, 1998 Manajemen Pemasaran : bauran pemasaran

Mujianah I, iriyanto HE, Nasran H,Poenomo A. 1986. Studi berbagai cara pengolahan pindang cue dalam rangka standarisasi. J. Penelitian Paca Panen Perikanan 56:25-33.
Soekarto ST. 1985. Penilain Organoleptik untuk Industri Pangan dan Hasil Pertanian. Jakarta : Bharata Karya Aksara.

Sugiono, 2001. Metode Penelitian Bisnis. Bandung: Alfabeta.

[SNI] Standar Nasional Indonesia. 1991. Petunjuk Pengujian Organoleptik Produk Perikanan. SNI 01-23461991. . 1992. ikan pindang. SNI 02-27171992.

Wibowo s. 1995. Industri Pemindangan ikan. Jakarta : penebar Swadaya. 